\title{
PEMANFATAN PEKARANGAN SEMPIT DENGAN HIDROPONIK SEDERHANA DI PEKANBARU
}

\author{
Surtinah $^{1 *}$, Rini Nizar ${ }^{1}$ \\ ${ }^{1}$ Prodi Agroteknologi, dan ${ }^{2}$ Prodi Agribisnis Fakultas Pertanian, Universitas Lancang Kuning, \\ Jl. Yos Sudarso, Km. 8 Rumbai Pekanbaru \\ * Penulis Korespodensi : surtinah@unilak.ac.id
}

\begin{abstract}
Abstrak
Teknik budidaya konvensional dengan menggunakan media tanam tanah menimbulkan masalah. Masalah yang dihadapi adalah ketersediaan tanah untuk proses budidaya sulit didapat, dan harganya mahal. Tim Pengabdian kepada Masyarakat Fakultas Pertanian Universitas Lancang Kuning (Faperta UNILAK) memperkenalkan Sistem budidaya hidroponik, dengan memanfaatkan bahan-bahan yang harganya lebih murah. Kelompok mitra pada umumnya lebih menggemari budidaya dengan menggunakan air sebagai media tanam dibandingkan dengan media tanah, karena lebih bersih, dan bisa dijadikan pajangan yang bernilai estetika lebih tinggi. Tujuan kegiatan IbM ini adalah untuk meningkatkan pengetahuan mitra dalam melakukan budidaya sayur dengan sistem hidroponik. Metode yang digunakan untuk mencapai tujuan adalah dengan cara: 1) penyuluhan. 2) demontrasi. 3) bantuan paket teknologi, dan 4) pendampingan. Hasil kegiatan disimpulkan bahwa pengetahuan peserta tentang budidaya hidroponik meningkat setelah mengikuti kegiatan P2M ini. Peningkatan pengetahuan ini disebabkan adanya demonstrasi, dan peserta dibekali alat dan bahan untuk mempraktekan sendiri. Sehingga minat untuk melakukan budidaya hidroponik peserta juga meningkat.
\end{abstract}

Kata Kunci: Hidroponik, Budidaya, dan Air.

\begin{abstract}
Conventional cultivation techniques by using a planting medium ground pose a problem. The problem faced is the availability of land for cultivation process is hard to come by, and expensive. The community service team from Faperta UNILAK introduce hydroponic cultivation system, by utilizing materials that are cheaper. Partner groups are generally more fond of cultivation by using water as a growing medium compared to medium soil, because it is free, and can be used as a display estetique higher. The objective of community service activity is to increase the knowledge partner in doing vegetable farming with hydroponics system. The method used to achieve the objectives are to: 1) extension. 2) demonstration. 3) aid package technology, and 4) assistance. The results concluded that the activities of the participants' knowledge about hydroponic cultivation increased after following this P2M activity. Increased knowledge is due to the demonstrations, and participants were given tools and materials for the practice itself. So the interest to do hydroponic cultivation of participants also increased.
\end{abstract}

Keywords: Hydroponics, cultivation, and Water.

\section{PENDAHULUAN \\ Analisis Situasi}

Tahun 2009 Presiden Republik Indonesia mengeluarkan Peraturan tentang Kebijakan percepatan Penganekaragaman Konsumsi pangan berbasis Sumberdaya Lokal, yang dituangkan dalam PP Nomor 22 tahun 2009 (Anonim, 2009). Hal inimenimbulkan banyak inovasi agar program tersebu tterlaksana sampai ke daerah. PP ini menjadi dasar untuk pengembangan rumah pangan lestrai, yang akan melahirkan gerakan untuk mengoptimalkan teras rumah yang dikenal dengan GPOP.

Teras rumah merupakan suatu areal disekitar rumah yang dibatasi oleh ukuran sesuai dengan legalisasinya. Dan teras rumah bisa dalam ukuran yang luas, namun bisa juga ukurannya kecil. Pada umumnya rumah di kota memiliki teras rumah yang sangat terbatas, apalagi perumahan yang dibangun berdasarkan atas program kepemilikan rumah yang diprakarsai pemerintah untuk golongan menengah kebawah yaitu perumahan sederhana. 
Perumahan sederhana yang dibangun pemerintah pada umumnya terletak di daerah perkotaan atau pinggiran kota. Begitu juga perumahan mitra terletak tidak jauh dari ibukota Propinsi. Sehingga, lokasi ini masih termasuk ke dalam wilayah kota Pekanbaru.

Optimalisasi teras rumah merupakan salah satu bentuk implementasi ketahanan pangan, sehingga fungsi teras rumah berubah menjadi lahan yang produktif. Teras rumah diharapkan mampu memenuhi kebutuhan sayuran pada tingkat rumah tangga sehingga tingkat konsumsi sayuran di Indonesia bisa meningkat.Untuk kondisi seperti ini maka bentuk pertanian kota yang dapat ditawarkan adalah dengan memanfaatkan kemajuan teknologi seperti hidroponik dan berbagai bentuk pertanian vertikal (Setiawan \& Rahmi, 2010).

Konsumsi sayuran di Indonesia masih rendah yaitu 40,8 kg/kapita per tahun. Standar FAO tingkat konsumsi per kapita per tahunadalah $75 \mathrm{~kg}$, standar untuk Indonesia sehat adalah 91,25 kg (Bahar, 2010).

Sampeliling et al, (2012) mengemukakan bahwa ada beberapa hal yang perlu diperhatikan dalam mengembangkan pertanian kota antara adalah 1) adanya teras rumah; 2) pengembangan tanaman produktif dengan penerapan teknologi ramah lingkungan dengan peningkatan populasi tanaman pangan dan non pangan; dan 3) penyuluhan.

Sayuran yang sehat dan bebas pestisida menjadi harapansetiap ibu rumah tangga, namun untuk mendapatkan sayuran yang higienis sangat sulit, karena hampir semua petani menggunakan pestisida dalam proses budidaya tanaman sayur di Kota Pekanbaru. Oleh karena itu melalui kegiatan ini diharapkan akan terjadi transfer ilmu pengetahuan tentang teknik budidaya sayur di halaman rumah yang bebas pestisida.

Mitra kegiatan yang menjadi objek kondisinya hampir sama. Mereka memiliki rumah dengan halaman yang terbatas,bahkan ada yang tidak memiliki halaman, namun ingin menghasilkan sayur dari sekitar rumahnya. Pada umumnya rumah mereka memiliki teras yang tidak dimanfaatkan, dan hanya sebagai aksesoris rumah saja, dan teras rumah inilah dapat digunakan untuk melakukan budidaya hidroponik sederhana. Mitra pada umumnya adalah ibu rumahtangga, sehingga pemilihan dan persediaan bahan pangan yang sehat ada di tangan mereka Kekhawatiran mereka tentang residu pestisida meningkatkan niat mereka untuk menghasilkan sayur sendiri, paling tidak dapat mengurangi mengkonsumsi sayur dari pasar.

Budidaya sayur secara konvensional yang selama ini dilakukan oleh kelompok ibu-ibu dalam mengelola teras rumahnya menemukan banyak masalah, antaralain sulitnya untuk mendapatkan media tanam yang berupa tanah subur. Bila ada maka harganya mahal, sehingga bila dihitung biaya untuk membeli media tanam dengan yang akan dihasilkan maka diputuskan untuk membeli sayur di pasar saja. Dengan kondisi yang demikian maka Tim P2M Fakultas Pertanian akan mensosialisasikan system budidaya tanaman dengan menggunakan sistem media tanam air. Karena air merupakan bahan cair yang ada di setiap rumahtangga.

Teknik budidaya dengan menggunakan air sebagai media tanam dikenal dengan istilah Hidroponik. Diharapkan mitra akan menggemari budidaya dengan menggunakan air sebagai media tanam dibandingkan dengan media tanah, karena lebih bersih, dan bisa dijadikan sebagai media pajangan yang bernilai estetika lebih tinggi.

Pemanfaatan halaman/teras rumah untuk tanaman pangan juga dapat dijadikan sebagai bagian dari gaya hidup (life Style) dalam memenuhi kebutuhan pangan rumah tangga, dengan sikap seperti ini maka kemandirian pangan dalam skala rumah tangga dapat dicapai (Kustiwan \& Ladimananda, 2012)

\section{Permasalahan}

Permasalahan yang dihadapi oleh mitra adalah:

1) Rendahnya pengetahuan tentang teknik budidaya sayur dengan sistem hidroponik.

2) Belum adanya pelatihan dan sosialisasi tentang teknik budidaya sayur secara hidroponik.

3) Kurangnya pemahaman bahwa halaman sempit/teras rumah juga dapat menghemat pengeluaran keluarga.

\section{TARGET DAN LUARAN}

\section{Target yang ingin dicapai}

Pengetahun mitra meningkat dengan kegiatan IbM ini, dan mitra mampu melaksanakan budidaya dengan sistem hidroponik di halaman/teras rumah masing-masing, dari menyemai benih sampai dengan budidaya hidroponik sederhana.

\section{Luaran yang ingin dicapai}

Luaran yang diharapkan adalah publikasi ilmiah dalam bentuk artikel yang dipublikasikan, sehingga dapat dibaca oleh banyak orang baik dari lingkungan perguruan tinggi maupun masyarakat awam.

\section{METODE PELAKSANAAN}

Kegiatan IbM ini dilakukan kepada mitra yaitu kelompok ibu-ibu yang tergabung yang berdomisili di Kelurahan Umbansari Rumbai, yang tergabung dalam kelompok "Salimah" (silaturahmi keluarga muslimah), yang terdiri dari kelompok Salimah Palas, dan Salimah Umbansari.

Metode yang dilaksanakan untuk mencapai tujuan adalah :

1) Penyuluhan untuk meningkatkan pengetahuan tentang hidroponik dengan menayangkan audio visual untuk memberikan motivasi kepada peserta dan memperlihatkan bahwa system yang akan dibuat dilakukan ini mudah.

2) Mendemontrasikan cara membudidayakan tanaman sayur dengan memperkenalkan kepada peserta alat dan bahan yang digunakan. Teknik budidaya yang dilakukan dari mulai persemaian sampai cara panen. 
3) Pemberian bantuan paket teknologi budidaya sayur di teras rumah kepada mitra, dari benih sampai alat-alat yang digunakan dan bahanbahan yang dibutuhkan dalam proses budidaya sayur dengan sistem hidroponik agar pengetahuan yang sudah ditransfer dapat dilaksanakan.

4) Pendampingan selama proses budidaya sayur sampai panen. Hal ini ditujukan agar mitra benar-benar merasakan manfaat dari kegiatan IbM ini, dan dapat merasakan bahwa kegiatan IbM ini tidak bersifat insidentil saja, kapanpun mereka perlu bantuan pengetahuan, maka pengusul akan menanggapinya.

\section{HASIL DAN PEMBAHASAN Hasil Kegiatan}

Kegiatan pengabdian kepada masyarakat yang tadinya direncanakanakan diadakan di kantor lurah Umban Sari diganti lokasinya ke Aula Fakultas Pertanian mengingat ketersediaan kapasitas ruangan dan sarana yang akan digunakan dalam kegiatan ini. Kegiatan IbM ini dihadiri peserta yang menjadi mitra IbM yaitu kelompok iburumahtangga Kelurahan Umbansari yang tergabung dalam "Salimah" (silaturahmi keluarga muslimah).

Peserta yang hadir dalam kegiatan yang dilakukanoleh Tim Dosen Fakultas Pertanian sangat antusias mengikuti kegiatan ini, terlihat dari respon yang diberikan oleh peserta melalui banyaknya pertanyaan-pertanyaan yang diajukan oleh peserta. Mereka sangat tertarik melihat alat peraga yang ada pada kegiatan ini. Selain itu ibu-ibu ini juga sangat senang dengan adanya pemberian paket teknologi yang diberikan oleh tim P2M berupa bibit, nutrisi tumbuhan dan penuntun cara budidaya hidroponik.

\section{Pembahasan}

Dalam melaksanakan kegiatan IbM tersebut Tim Faperta Unilak membuat suatu instrumen pengukuran berupa kuesioner yang harus diisi sebelum dan sesudah acara dilaksanakan. Dan hasil pengukuran sebelum dan sesudah kegiatan ditampilkan pada Tabel berikut ini.

Tabel 1. Hasil pengukuran sebelum kegiatan dilaksanakan

\begin{tabular}{|l|l|c|c|}
\hline No & \multicolumn{1}{|c|}{ Pernyataan } & $\begin{array}{c}\text { Jawaban } \\
\text { Ya }\end{array}$ & $\begin{array}{c}\text { Jawaban } \\
\text { Tidak }\end{array}$ \\
\hline 1 & $\begin{array}{l}\text { Pengetahuan tentang } \\
\text { pengelolaan teras } \\
\text { rumah }\end{array}$ & $21 \%$ & $79 \%$ \\
\hline 2 & $\begin{array}{l}\text { Mengetahui istilah } \\
\text { hidroponik }\end{array}$ & $87 \%$ & $13 \%$ \\
\hline 3 & $\begin{array}{l}\text { Berminat } \\
\text { memanfaatkan teras } \\
\text { rumah dgn sist } \\
\text { hidroponik }\end{array}$ & $88 \%$ & $12 \%$ \\
\hline 4 & $\begin{array}{l}\text { Cara budidaya } \\
\text { hidroponik }\end{array}$ & $42 \%$ & $58 \%$ \\
\hline
\end{tabular}

\begin{tabular}{|l|l|c|c|}
\hline 5 & $\begin{array}{l}\text { Cara pemberian } \\
\text { nutrisi hidroponik }\end{array}$ & $42 \%$ & $58 \%$ \\
\hline 6 & $\begin{array}{l}\text { Kesulitan dalam } \\
\text { budidaya hidroponik }\end{array}$ & $29 \%$ & $71 \%$ \\
\hline 7 & $\begin{array}{l}\text { Berminat utk ikut } \\
\text { dalam pelatihan } \\
\text { serupa }\end{array}$ & $96 \%$ & $4 \%$ \\
\hline 8 & $\begin{array}{l}\text { P2M bermanfaat bagi } \\
\text { peserta }\end{array}$ & $96 \%$ & $4 \%$ \\
\hline
\end{tabular}

Hasil pengukuran di atas menggambarkan bahwa peserta pada umumnya berminat untuk memanfaatkan teras rumah dengan tanaman sayuran dengan cara budidaya hidroponik, hanya $12 \%$ yang belum berminat. Hal ini disebabkan karena mereka menganggap bahwa budidaya hidroponik sulit untuk dilaksanakan dan membutuhkan biaya yang besar. Pandangan seperti inilah yang ingin dihilangkan, karena dengan kondisi lokasi tempat tinggal mitra, yang paling tepat melakukan budidaya di pekarangan sempit adalah dengan sistem budidaya hidroponik.

Tabel 2. Hasil pengukuran sesudah kegiatan

\begin{tabular}{|c|c|c|c|}
\hline No & Pernyataan & $\begin{array}{c}\text { Jawaban } \\
\text { Ya }\end{array}$ & $\begin{array}{c}\text { Jawaban } \\
\text { Tidak }\end{array}$ \\
\hline 1 & $\begin{array}{l}\text { Pengetahuan tentang } \\
\text { pengelolaan teras } \\
\text { rumah }\end{array}$ & $100 \%$ & $0 \%$ \\
\hline 2 & $\begin{array}{l}\text { Mengetahui istilah } \\
\text { hidroponik }\end{array}$ & $100 \%$ & $0 \%$ \\
\hline 3 & $\begin{array}{l}\text { Berminat } \\
\text { memanfaatkan teras } \\
\text { rumah dgn sist } \\
\text { hidroponik }\end{array}$ & $98 \%$ & $2 \%$ \\
\hline 4 & $\begin{array}{l}\text { Cara budidaya } \\
\text { hidroponik }\end{array}$ & $98 \%$ & $2 \%$ \\
\hline 5 & $\begin{array}{l}\text { Cara pemberian } \\
\text { nutrisi hidroponik }\end{array}$ & $97 \%$ & $3 \%$ \\
\hline 6 & $\begin{array}{l}\text { Kesulitan dalam } \\
\text { budidaya hidroponik }\end{array}$ & $98 \%$ & $2 \%$ \\
\hline 7 & $\begin{array}{l}\text { Berminat utk ikut } \\
\text { dalam pelatihan } \\
\text { serupa }\end{array}$ & $98 \%$ & $2 \%$ \\
\hline 8 & $\begin{array}{l}\text { P2M bermanfaat bagi } \\
\text { peserta }\end{array}$ & $100 \%$ & $0 \%$ \\
\hline
\end{tabular}

Setelah kegiatan dilaksanakan terjadi peningkatan terhadap pengetahuan tentang hidroponik, teknik budidaya hidroponik, dan seluruh item kuesioner sebagai alat ukur yang digunakan terjadi peningkatan. Hal ini sudah dapat menjawab tujuan dari kegiatan ini adalah meningkatkan pengetahuan mitra dapat dicapai. 
Tabel 3. Peningkatan pengetahuan peserta sesudah mengikuti kegiatan

\begin{tabular}{|c|c|c|c|}
\hline No & Pernyataan & $\begin{array}{l}\text { Peningkatan } \\
\text { Pengetahuan }\end{array}$ & Keterangan \\
\hline 1 & $\begin{array}{l}\text { Pengetahuan } \\
\text { tentang } \\
\text { pengelolaan } \\
\text { teras rumah }\end{array}$ & $79 \%$ & Meningkat \\
\hline 2 & $\begin{array}{l}\text { Mengetahui } \\
\text { istilah } \\
\text { hidroponik }\end{array}$ & $13 \%$ & Meningkat \\
\hline 3 & $\begin{array}{l}\text { Berminat } \\
\text { memanfaatkan } \\
\text { teras rumah dgn } \\
\text { sist hidroponik }\end{array}$ & $10 \%$ & Meningkat \\
\hline 4 & $\begin{array}{l}\text { Cara budidaya } \\
\text { hidroponik }\end{array}$ & $52 \%$ & Meningkat \\
\hline 5 & $\begin{array}{l}\text { Cara pemberian } \\
\text { nutrisi } \\
\text { hidroponik }\end{array}$ & $55 \%$ & Meningkat \\
\hline 6 & $\begin{array}{l}\text { Kesulitan dalam } \\
\text { budidaya } \\
\text { hidroponik }\end{array}$ & $69 \%$ & Meningkat \\
\hline 7 & $\begin{array}{l}\text { Berminat utk } \\
\text { ikut dalam } \\
\text { pelatihan serupa }\end{array}$ & $2 \%$ & Meningkat \\
\hline 8 & $\begin{array}{l}\text { P2M } \\
\text { bermanfaat bagi } \\
\text { peserta }\end{array}$ & $100 \%$ & Meningkat \\
\hline
\end{tabular}

Perubahan sikap maupun perubahan pengetahuan adalah hasil dari suatu proses belajar. Demikian juga dengan kegiatan IbM yang telah dilakukan oleh Tim Faperta Unilak memperlihatkan perubahan pada peserta baik pengetahuannya maupun keinginannya untuk melaksanakan budidaya dengan sistem hidroponik.

Pertanyaan yang muncul pada saat kegiatan adalah tentang instalasi hidroponik yang permanen. Instalasi hidroponik yang permanen membutuhkan biaya yang cukup besar, namun dapat bertahan sampai belasan tahun, seperti yang dicontohkan. Seangkan instalasi hidroponik sederhana tidak memerlukan biaya yang tinggi, karena peserta dapat memanfaatkan bendabenda yang ada di lingkungannya yang sudah tidak digunakan lagi menjadi sesuatu yang bermanfaat dalam memenuhi kebutuhan keluarga terhadap kebutuhan pangan yang sehat. Salah satu contoh wadah yang dapat dimanfaatkan untuk budidaya hidroponik adalah botol air mineral.

Teknik budidaya hidroponik yang disampaikan oleh Tim Dosen Faperta Unilak adalah teknik budidaya bebas pestisida, sehingga keterjaminan kesehatan dapat dicapai tanpa khawatir tentang bahaya residu pestisida. Agar kegiatan ini dapat di uji coba, maka Tim menyerahkan seperangkat peralatan dan bahan yang dapat digunakan untuk kegiatan tersebut, seperti terlihat pada foto di bawah ini.
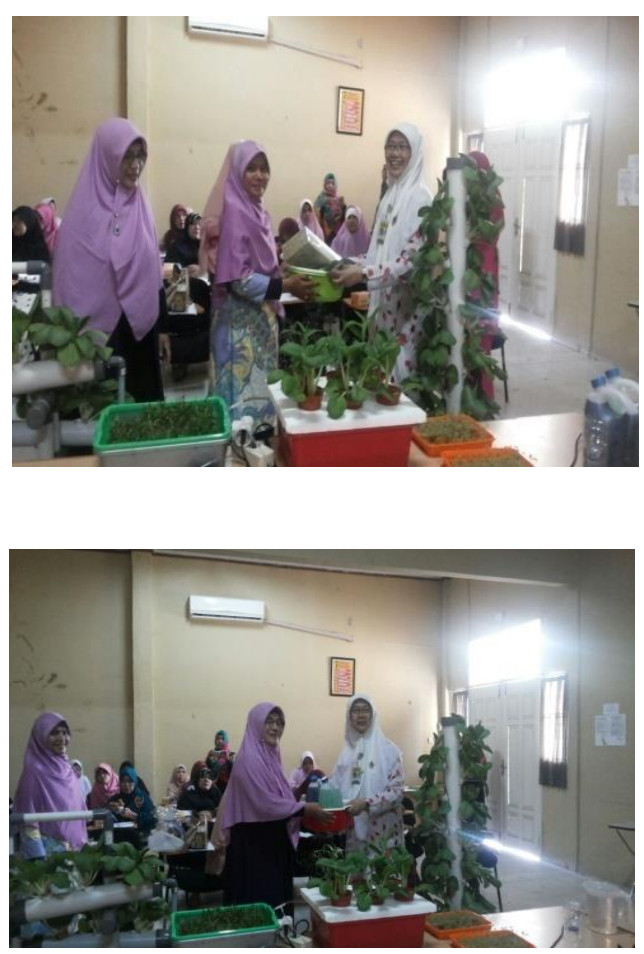

Gambar 1. Penyerahan paket teknologi hidroponik sederhana yang diterima oleh Ketua Salimah Umbansari, dan Ketua Salimah Palas.

Implementasi kegiatan yang dilakukan oleh kelompok salimah dibuktikan melalui foto yang dikirimkan ke Tim P2m Faperta di bawah ini sebagai umpan balik dari kegiatan yang sudah dilaksanakan.
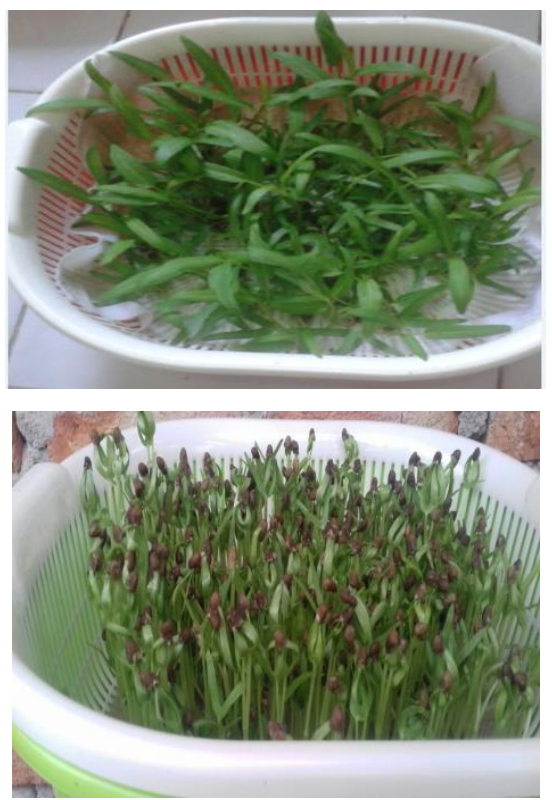

Gambar 2. Hasil uji coba peserta kelompok "salimah Umbansari" (kiri) dan kelompok "salimah Palas" (kanan) 


\section{KESIMPULAN}

Pengetahuan peserta tentang budidaya hidroponik dengan memanfaatkan teras rumah meningkat setelah mengikuti kegiatan P2M ini. Peningkatan pengetahuan ini disebabkan karena pelatihan yang langsung dilaksanakan oleh peserta pada kegiatan ini. Sehingga mina tuntuk melakukan budidaya hidroponik di teras rumah peserta juga meningkat.

Peningkatan pengetahuan ini dipantau tidak hanya pada saat mengikuti pelatihan, namun Tim juga melakukan pemantauan setelah kegiatan selesai ke rumah peserta, apakah penegetahuan dan peralatan yang didapat dan disumbangkan digunakan untuk latihan di rumah masing-masing, ternyata apa yang diharapkan oleh Tim P2M Faperta Unilak dilaksanakan oleh peserta.

Sehingga dapat disimpulkan bahwa kegiatan ini sangat bermanfaat bagi masyarakat dalam menyediakan pangan yang sehat yang dapat diperoleh melalui pekarangan sempit dengan sistem hidroponik sederhana.

Peserta berharap bahwa hidroponik yang diperkenalkan tidak hanya yang sederhana, namun hidroponik yang lengkap dengan instalasi modern, agar halaman yang masih bisa dimanfaatkan dapat digunakan sebagai lahan produksi sebagai sumber penghasilan dan sebagai sumber pangan sehat.

\section{DAFTAR PUSTAKA}

Anonim. (2009). Peraturan tentang Kebijakan Percepatan Penganekaragaman Konsumsi Pangan Berbasis Sumberdaya Lokal. Jakarta.

Bahar, Y. . (2010). Tingkatkan Konsumsi Sayuran Melalui Budidaya Teras Rumah. Jakarta.

Kustiwan, I., \& Ladimananda, A. (2012). Pemodelan Dinamika Perkembangan Perkotaan dan Daya Dukung Lahan di Kawasan Cekungan Bandung. J. Tata Loka, 14(2), 98-112.

Sampeliling, S., Sitorus, S. R. P., Nurisyah, S., \& Pramudya, B. (2012). Kebijakan Pengembangan Pertanian Kota Berkelanjutan Studi Kasus di DKI Jakarta. J. Analisis Kebijakan Pertanian, 10(3), 257-267.

Setiawan, B., \& Rahmi, D. . (2010). Ketahanan Pangan, Lapangan Kerja, dan Keberlanjutan Kota: Studi Pertanian Kota di Enam Kota Indonesia. Yogyakarta: Pusat Studi Lingkungan Hidup. Universitas Gajahmada. 